\title{
El feminicidio en Ciudad Juárez: una perspectiva jurídica*
}

\section{Olivia Aguirre Bonilla*}

Para citar este artículo

Aguirre, O. (2021). El feminicidio en Ciudad Juárez: una perspectiva jurídica. Via luris, 30, 113-129. DOI: https://doi.org/10.37511/viaiuris.n30a6

\section{RESUMEN}

La violencia contra las mujeres continúa presente hoy en día en nuestra sociedad, y sus distintas modalidades se hacen visibles e incluso comunes. Entre ellas, el feminicidio surge como un crimen perpetrado contra la mujer por el hecho de ser mujer. Nuestro espacio de estudio se centra en la entidad federativa de Chihuahua, México, particularmente en la ciudad fronteriza de Juárez. La presente investigación tiene como objetivo definir los conceptos de femicidio y feminicidio desde el ámbito teórico y normativo. Además, busca analizar las dimensiones y alcances del delito de homicidio por razón de género en el Código Penal del estado de Chihuahua, e identificar las similitudes y diferencias de tipo penal en otras entidades del Estado mexicano, así como conocer las percepciones de las autoridades investigadoras y judiciales respecto al tipo penal. La metodología se basó en el enfoque cualitativo, a través de los métodos inductivo, comparativo y exegético, con la entrevista semiestructurada y la investigación documental como técnicas principales. Así, se hace indispensable repensar el delito de feminicidio en la entidad de Chihuahua y adaptarlo a la realidad, a través de una reforma integral que logre visibilizar la violencia de género y promover la conciencia social sobre el problema.

* Artículo de reflexión producto del proyecto de investigación titulado "El feminicidio en el estado de Chihuahua, México: un enfoque normativo". Vinculado a la Universidad Autónoma de Ciudad Juárez. (Periodo 2020). Chihuahua (México).

** Doctora en Desarrollo y Ciudadanía: Derechos Humanos, Igualdad, Educación e Intervención Social por la Universidad Pablo Olavide, Sevilla, España. Docente investigadora en la Universidad Autónoma de Ciudad Juárez, Chihuahua, México. Correo electrónico: olivia. aguirre@uacj.mx. ORCID: https://orcid.org/0000-0001-8655-5485. 


\title{
Femicide in Ciudad Juárez: a legal perspective
}

\section{Olivia Aguirre Bonilla}

\begin{abstract}
Violence against women is present today in our society, different modalities are those that become visible and even common, in them we find femicide as that crime perpetrated against women for the fact of being a woman. Our study space focuses on the federal entity of Chihuahua, Mexico, with special emphasis on the border city of Ciudad Juárez for being one of the cities where feminicides continue to be present, perceived and assimilated as part of normality by the authorities and by the society. The research has started from the qualitative approach, through the inductive method, the comparative method and the exegetical method. as an indispensable contribution to rethink the crime of femicide in the state of Chihuahua and adapt it to reality, thereby understanding the dimensions and scope of the norm that seeks the protection and promotion of women's human rights. The objetives of this research are aimed at defining the concepts of femicide and feminicide from the theoretical and normative scope: analyze the dimensions and scope of the crime of homicide based on gender in the Penal Code of the state of Chihuahua: Identify the similarities and differences of criminal type in the entities of the Mexican State and know the perceptions of the investigating and judicial authorities regarding the criminal type. The methodological base was the qualitative approach, through the inductive method, the comparative method and the exegetical method, whose techniques were the semi-structured interview and documentary research. It is essential to rethink the crime of femicide in the entity and adapt it to reality, through a comprehensive reform that makes gender violence visible and generates social awareness about the problem.
\end{abstract}

\section{Keywords}




\section{Femicídio em Ciudad Juárez: uma perspectiva legal}

\section{Olivia Aguirre Bonilla}

\section{RESUMO}

A violência contra a mulher está hoje presente em nossa sociedade, diferentes modalidades são visíveis e até comuns, entre elas encontramos o femicídio como um crime perpetrado contra a muIher pelo fato de ser mulher. Nossa área de estudo concentra-se na entidade federal de Chihuahua, México, com ênfase especial na cidade fronteiriça de Juarez. Os objetivos desta pesquisa são definir os conceitos de femicídio e feminicídio de uma perspectiva teórica e normativa; analisar as dimensões e o alcance do crime de homicídio relacionado ao gênero no Código Penal do Estado de Chihuahua; identificar as semelhanças e diferenças do tipo penal em outros estados mexicanos; e aprender sobre as percepções das autoridades investigadoras e judiciais com relação ao tipo penal. A base metodológica foi a abordagem qualitativa, através do método indutivo, método comparativo e método exegético, cujas técnicas foram a entrevista semi-estruturada e a pesquisa documental. É essencial repensar o crime de femicídio no Estado e adaptá-lo à realidade, através de uma reforma abrangente que torne visível a violência de gênero e gere consciência social sobre o problema.

Palavras-chave

Feminicídio; Femicídio; Ciudad Juárez; Chihuahua; Tipo criminoso; Violência de gênero. 


\section{Le féminicide à Ciudad Juárez: une perspective juridique}

\section{Olivia Aguirre Bonilla}

\section{RÉSUMÉ}

La violence contre les femmes est aujourd'hui présente dans notre société, différentes modalités sont visibles et même communes, parmi elles nous trouvons le fémicide comme un crime perpétré contre les femmes pour le fait d'être une femme. Notre domaine d'étude porte sur l'entité fédérale de Chihuahua, au Mexique, et plus particulièrement sur la ville frontalière de Juarez. Les objectifs de cette recherche sont de définir les concepts de fémicide et de féminicide d'un point de vue théorique et normatif ; d'analyser les dimensions et la portée du crime d’homicide lié au genre dans le Code pénal de l'état de Chihuahua ; d'identifier les similitudes et les différences du type pénal dans d'autres états mexicains; et de connaître les perceptions des autorités d'enquête et judiciaires en ce qui concerne le type pénal. La base méthodologique était l'approche qualitative, à travers la méthode inductive, la méthode comparative et la méthode exégétique, dont les techniques étaient l'entretien semi-structuré et la recherche documentaire. Il est essentiel de repenser le délit de fémicide dans l'État et de l'adapter à la réalité, par le biais d'une réforme globale qui rende la violence de genre visible, et génère une prise de conscience sociale du problème.

\section{Mots-clés}




\section{INTRODUCCIÓN}

La Heroica Ciudad Juárez corresponde a uno de los lugares donde se presentaron los primeros feminicidios en la entidad. A la fecha, continúan vigentes y son percibidos y asimilados como parte de la normalidad por parte de las autoridades y de la sociedad.

En esta investigación entendemos el feminicidio desde el enfoque de Lagarde y de los Ríos (2006), como aquel que obedece a razones de género y a la construcción social de impunidad que rodea las muertes de mujeres. Pero no solo consideramos los feminicidios como consecuencia de la impunidad, sino como una de sus causas. En esta línea, Segato (2016) propone comprender los feminicidios de Juárez como productores y reproductores de impunidad.

Hemos tomado como punto de referencia el estudio que realiza Rita Segato en Ciudad Juárez, titulado La escritura en el cuerpo de las mujeres asesinadas en Ciudad Juárez. De allí se desprende la acepción de la autora sobre el feminicidio, y en especial el sentido que Ciudad Juárez le confiere a esta palabra:

El asesinato de una mujer genérica, de un tipo de mujer, solo por ser mujer y por pertenecer a este tipo, de la misma forma que el genocidio es una agresión genérica y letal a todos aquellos que pertenecen al mismo grupo étnico, racial, lingüístico, religioso o ideológico. Ambos crímenes se dirigen a una categoría, no a un sujeto específico. Precisamente, este sujeto es despersonalizado como sujeto porque se hace predominar en él la categoría a la cual pertenece sobre sus rasgos individuales biográficos o de personalidad. (Segato, 2016, p. 47)

Además de lo anterior, Segato (2016) señala que el feminicidio se encuentra ligado a la misoginia, cuyo sentimiento inmerso es la disponibilidad del cuerpo para su apropiación.

Por muchos años, Ciudad Juárez ha sido una de las urbes con mayor índice de feminicidios, desapariciones de mujeres y violencia sexual hacia mujeres. Aguirre (2020) indica que este municipio fue elegido para la implementación de la Iniciativa Spotlight, un programa diseñado para fortalecer, complementar y apoyar los mecanismos e iniciativas existentes a nivel federal, estatal y municipal para erradicar el feminicidio y otras formas de violencia contra mujeres y niñas. Hasta noviembre de 2020, 170 mujeres fueron asesinadas, según información obtenida a través del portal de transparencia de la Fiscalía Especializada en Atención a Mujeres Víctimas del Delito por Razones de Género Zona Norte (2020). Para esta entidad, la erradicación de la violencia de género debe ir acompañada de acciones concretas, que incluyan reformas a la normatividad, especialización de las autoridades y campañas sociales de concientización, en especial frente a las relaciones de género. Como afirma Segato (2003), ello apunta hacia una ética feminista para toda la sociedad.

Los resultados de esta investigación han quedado estructurados en tres apartados, el primero de ellos titulado "Aproximación al término de femicidio y feminicidio". Allí analizamos ambos conceptos desde el ámbito teórico hasta el normativo, con la finalidad de determinar los elementos que lo integran e identificar el más adecuado en el contexto actual. El segundo apartado, titulado "El homicidio por razón de género en el Código Penal del estado de Chihuahua", brinda un análisis jurídico del tipo penal en el estado de Chihuahua, en comparación con los códigos penales de diversas entidades federativas, según los supuestos normativos y otros elementos indispensables del tipo penal. Al respecto, se homologan los mismos elementos y características en todas las entidades federativas, pues a medida que se contemplen los mismos supuestos normativos, podrá ser visible el feminicidio y con ello se facilitará la investigación y se podrá procurar justicia. El último apartado se titula "La percepción de los juzgadores y fiscales ante el tipo penal de homicidio por razones de género", y tiene como fin establecer la percepción de los juzgadores y fiscales involucrados en los procesos legales relacionados con este delito, pues en principio son los fiscales quienes enfrentan dificultades para integrar la carpeta de investigación y su posterior judicialización, mientras que los juzgadores se enfrentan a las lagunas de la ley y a la falta de capacitación para juzgar con perspectiva de género.

\section{METODOLOGÍA}

La investigación se abordó desde el enfoque cualitativo, a través del método inductivo y a partir de la experiencia de los actores involucrados para obtener un principio básico general. Además, se acudió al 
método comparativo al analizar las similitudes y diferencias del tipo penal entre diversas entidades federativas del Estado mexicano. Por último, se hizo uso del método exegético, relacionado con el sentido penal, para identificar si coincide con la realidad del estado de Chihuahua, y así comprender las dimensiones y los alcances de la norma. Por otro lado, la principal técnica utilizada fue la entrevista semiestructurada, que permite establecer la percepción de los agentes involucrados en la investigación del delito y sanción.

Para la realización de las entrevistas se hizo una búsqueda de funcionarios vinculados a la Fiscalía Especializada en Atención a Mujeres Víctimas del Delito por Razones de Género, zona norte, y funcionarios del Poder Judicial del Estado de Chihuahua que laboraran en el Distrito Judicial Bravos (donde se ubica Ciudad Juárez) y que hubiesen Ilevado procesos por el delito de homicidio por razones de género. Para ello se realizaron peticiones por escrito a ambas dependencias, lo que permitió el acercamiento con distintos funcionarios.

El instrumento de entrevista se dividió en cinco áreas: el tipo penal de homicidio por razones de género, la acreditación del tipo penal por parte del fiscal, supuestos del tipo penal, agravantes de la pena, experiencias en la investigación y enjuiciamiento por el delito de homicidio por razones de género. Cada área tiene a su vez varias categorías.

Los objetivos de la investigación consistieron en definir los conceptos de femicidio y feminicidio desde el ámbito teórico y normativo; analizar las dimensiones y alcances del delito de homicidio por razón de género en el Código Penal del estado de Chihuahua; identificar las similitudes y diferencias del tipo penal en otras entidades federativas del Estado mexicano y conocer las percepciones de las autoridades investigadoras y judiciales respecto al citado tipo penal.

Lo anterior constituye un aporte fundamental para repensar el delito de feminicidio en el estado de Chihuahua y adaptarlo a la realidad, teniendo en cuenta las dimensiones y los alcances de la norma, con miras a la protección y promoción de los derechos humanos de las mujeres. En este sentido, Segato (2003) señala la importancia de darle visibilidad a los derechos, pues estos construyen realidad desde la persuasión.

\section{RESULTADOS Y DISCUSIÓN}

\section{Aproximación a los términos femicidio y feminicidio}

El término femicidio fue introducido con un contenido jurídico y social a mediados de la década de los setenta por Diane Rusell, cuya intención era señalar que el asesinato de una mujer no debía entenderse como un homicidio. Para Russell (1992), el término homicide no implicaba a la mujer, y lo consideraba un término machista. Con la expresión femicidio, Russell apuntaba que los crímenes contra mujeres eran resultado de la violencia contra la mujer, y relacionaba la muerte de las mujeres con el hecho de ser mujer, en tanto su condición de género femenino. En esta línea, según datos de la Comisión Económica para América Latina y el Caribe (2018), cada día mueren en promedio 12 mujeres latinoamericanas y caribeñas por el solo hecho de ser mujeres.

En julio de 2012, en Denver, Colorado (Estados Unidos), durante la primera sesión plenaria del femicidio en la celebración anual de la Coalición Nacional de Violencia Doméstica (NCADV, por sus siglas en inglés), Russell instó a los miembros a adoptar el término femicidio, precisando además que era perpetrado por hombres: "Femicide is the term that I first publicly advocated in 1976 to refer to the killing of females by males because they are female as a feminist alternative to the terms homicide and murder" (Russell, 2012).

Así pues, se fueron sumando voces desde la academia para visibilizar este término, hasta desarrollar la acepción "feminicidio", que parte de femicide, y que fue utilizado en un primer momento por Marcela Lagarde y de los Ríos, quien considera importante agregar, entre otros elementos, el de la impunidad. Lagarde (2006) argumenta que este se "presta mejor a cubrir las razones de género y la construcción social detrás de estas muertes, así como la impunidad que las rodea" (p.12).

En este punto, las acepciones de feminicidio acuñadas tanto por Lagarde como por Segato adquieren especial importancia para la presente investigación, pues permiten analizar los asesinatos de mujeres en Ciudad Juárez, Chihuahua. Por ello, nos limitaremos a estos como parte del ámbito teórico. 
Lagarde (2012) advierte que, además de ejercer violencia contra la mujer por el solo hecho de serlo, los feminicidios son crímenes de odio cometidos casi siempre por hombres, desde una posición de superioridad y ventaja sobre las mujeres. En ese mismo sentido, Segato (2016) señala que la expresión feminicidio utiliza el cuerpo femenino como aquel que puede ser sacrificado en aras de un bien mayor, para rendir tributo dentro de una fratría mafiosa. Por otro lado, Segato (2016) analiza el sentido que se le confiere a la expresión feminicidio, refiriendo que:

Es el asesinato de una mujer genérica, de un tipo de mujer, solo por ser mujer y por pertenecer a este tipo, de la misma forma que el genocidio es una agresión genérica y letal a todos aquellos que pertenecen al mismo grupo étnico, racial, lingüístico, religioso o ideológico. Ambos crímenes se dirigen a una categoría, no a un sujeto específico. Precisamente, este sujeto es despersonalizado como sujeto porque se hace predominar en él la categoría a la cual pertenece sobre sus rasgos individuales biográficos o de personalidad. (p. 47)

Ambas autoras concluyen que los elementos más importantes presentes en este fenómeno son la impunidad, la supremacía, la ventaja sobre la mujer y el sentido de la apropiación del cuerpo de la mujer como una cosa u objeto.

En el ámbito internacional se han utilizado indistintamente las expresiones femicidio y feminicidio para referirse a lo mismo. Así, se han celebrado distintos encuentros con declaraciones al respecto, que no distinguen los dos términos. Tal es el caso de la Declaración sobre el Femicidio aprobada el 15 de agosto de 2008 por el Comité de Expertas del Mecanismo de Seguimiento de la Convención de Belém do Pará (MESECVI) de la Organización de los Estados Americanos (OEA). Esta declaración busca reconocer el grave problema del femicidio en América Latina y el Caribe, y expresa su preocupación por el creciente número de asesinatos de mujeres en la región como la manifestación más grave de discriminación y violencia contra las mujeres. Allí se considera que un femicidio es la muerte violenta de una mujer por razones de género, y que puede ocurrir tanto dentro de la familia como en cualquier otro tipo de relación entre la víctima y el victimario. Además, puede darse al interior de una comunidad, con la característica de haber sido realizada o tolerada por el Estado y sus agentes, ya sea por acción u omisión. Por último, esta declaración recomienda a los Estados cinco acciones para atender el fenómeno:

1. Que el término "emoción violenta" no sea utilizado para disminuir la responsabilidad de los autores de femicidio.

2. Legislar o en su caso fortalecer la legislación existente respecto a la autonomía de las mujeres, sus derechos y libertades. Para que con ello las mujeres que son víctimas de violencia de género puedan encontrar respaldo para lograr de esas relaciones y proteger su vida e integridad.

3. Incluir los riesgos de vida e integridad física y otras manifestaciones de violencia contra las mujeres en sus políticas de seguridad ciudadana.

4. Garantizar un eficaz acceso de las mujeres a la justicia; mejorando el sistema de investigación y brindando protección inmediata a través de las distintas medidas cautelares previstas para la protección a las mujeres afectadas por violencia, incluso de ser necesarias periciales forenses, lo anterior aunado a un proceso judicial pronto y expedito que sancione tanto al agresor como a los funcionarios que no juzguen con perspectiva de género y que no actúen en el marco de una debida diligencia.

5. Contar con bases de datos, investigaciones y estadísticas que permitan conocer la magnitud de la problemática de femicidio en el país, en las entidades federativas y en los municipios para que con ello se pueda monitorear los avances y retrocesos del país en esa materia. (OEA, 2008, p. 8)

Así mismo, dicho documento establece un apartado especial para los medios de comunicación, en donde recomienda adoptar códigos de ética para el tratamiento de los casos de violencia contra las mujeres y en especial de los femicidios, promover el respeto a la dignidad e integridad de las víctimas y evitar la difusión de detalles morbosos y de estereotipos sexistas o descalificadores sobre las mujeres. También señala que los medios de comunicación deben cumplir con su rol de educación ética ciudadana, además de promover la equidad e igualdad de género para contribuir a la erradicación de la violencia contra las mujeres. 
Posteriormente, la Corte Interamericana de Derechos Humanos (Corte IDH) viene a sentar criterios sobre este fenómeno en la sentencia del Caso González y otras vs. México (Campo Algodonero) de 2009, en donde no utilizó la expresión femicidio o feminicidio, sino que se refirió a los "homicidios de mujeres por razones de género". Los hechos del presente caso se sitúan en Ciudad Juárez:

Es bajo este contexto que, los días 6 y 7 de noviembre del año 2001, fueron encontrados en Ciudad Juárez los cuerpos de ocho mujeres asesinadas, todos en un campo utilizado para la siembra de algodón. Entre estos cuerpos se encontraban los de las jóvenes Claudia Ivette González de 20 años de edad, Esmeralda Herrera Monreal de 15 años de edad y Laura Berenice Ramos Monárrez de 17 años de edad, cada una de ellas desaparecidas en lugares y fechas distintas a la otra. Los familiares de las víctimas realizaron el reporte de desaparición dentro de las primeras 72 horas del hecho. (Aguirre, 2014, p. 172)

Aguirre (2014) precisa que el Estado mexicano fue declarado culpable por no garantizar la vida, la integridad y la libertad de las víctimas en dicho caso, además de la violación de los derechos de las víctimas indirectas como en el caso de sus familiares, quienes enfrentaron discriminación, malos tratos y hostigamientos, lo cual dejó secuelas y sufrimiento.

Pero no fue sino hasta 2013 cuando el Consejo Económico y Social de la Organización de las Naciones Unidas (ONU) se pronunció sobre esta problemática a través de la Declaración de Viena sobre el Femicidio (2013), declaración que se derivó del Simposio de Viena sobre Femicidio, celebrado en noviembre de 2012 en la sede de las Naciones Unidas en Viena. Allí se reconoce que la situación de violencia contra las mujeres resulta alarmante en todo el mundo, y se alerta sobre el aumento del feminicidio a nivel global. Uno de los elementos comunes que se presentan en este tipo de delitos es que tienden a permanecer impunes, lo cual conlleva la revictimización, en un primer momento, de las víctimas directas $y$, en un segundo momento, de los familiares de las víctimas. Con ello, la sociedad recibe un mensaje de tolerancia frente a la violencia contra las mujeres.

De igual manera, la declaración reafirma el compromiso de los Estados miembros de trabajar juntos para poner fin al femicidio, en pleno cumplimiento de los instrumentos legales nacionales e internacionales. Así, se resalta la obligación de los Estados miembros frente a la protección de las mujeres y frente a la prevención y el enjuiciamiento del femicidio, de conformidad con los tratados internacionales. Además, los invita a considerar la adopción e implementación de legislación para investigar, enjuiciar, castigar y reparar el feminicidio.

En este orden, la Asamblea General de las Naciones Unidas, para atender a la Declaración de Viena sobre el Femicidio y con el fin de fortalecer la respuesta de los sistemas penales, así como adoptar medidas destinadas a apoyar la capacidad de los Estados para investigar, perseguir y sancionar las muertes violentas de mujeres por razones de género, diseña el Modelo de protocolo latinoamericano de investigación de las muertes violentas de mujeres por razones de género (femicidios/feminicidio) (2014). Este surge como un instrumento práctico que debe ser utilizado en las investigaciones de muertes violentas de mujeres, con la perspectiva de género como eje transversal es su abordaje. Para ello, es necesario incluir, además, un enfoque multidisciplinario (derecho, sociología, medicina legal y criminalística), e integrar a las investigaciones de tipo penal factores individuales, institucionales y estructurales que permitan entender el delito y brindar una respuesta apropiada.

Frente a la definición de los conceptos femicidio y feminicidio, el Modelo de Protocolo ha señalado que su alcance, contenido e implicaciones todavía son objeto de amplios debates tanto en las ciencias sociales como en la acción política y en los procesos legislativos nacionales. Sus acepciones varían según el enfoque desde el cual se examina y la disciplina que lo aborda, y aunque se reconoce que hay diferencias conceptuales, también es cierto que los marcos normativos de la región los utilizan indistintamente para referirse a la muerte violenta de mujeres por razones de género. Así, el Modelo adopta la definición del término femicidio que da MESECVI a través de la Declaración sobre el Femicidio antes mencionada.

Sin embargo, en México se ha incorporado la expresión "feminicidio" como tipo penal en los distintos códigos, e incluso es el término más utilizado tanto en los medios de comunicación como en la academia. Desde el enfoque aquí utilizado, nos parece oportuno partir de los conceptos que 
nos dan Lagarde y Segato, pues consideramos que la expresión "feminicidio" describe la realidad en Ciudad Juárez.

\section{El delito de homicidio por razón de género en el Código Penal del Estado de Chihuahua}

El estado de Chihuahua es una de las entidades federativas de la República Mexicana en donde se han visibilizado en mayor medida los crímenes contras las mujeres, en especial en el municipio de Ciudad Juárez, ciudad fronteriza que colinda con El Paso, Texas. Ciudad Juárez se ha considerado la frontera del tráfico más lucrativo del mundo, como bien lo ha precisado Segato(2016):

La existencia de tráfico de drogas, tráfico de cuerpos. Aquella frontera que separa una de las manos de obra más caras del mundo de una de las manos de obra más baratas. Y es esa frontera el escenario del mayor y más prolongado número de ataques y asesinatos de mujeres, con modus operandi semejante del que se tiene noticia en tiempos de paz. (p. 20)

Esta ciudad alberga una multiplicidad de factores sociales que posicionan a las mujeres en situación de vulnerabilidad. Por ejemplo, Méndez (2010) relaciona la violencia en Ciudad Juárez con el territorio maquilador que alimenta la violencia simbólica. En este orden, Vargas (2018) entiende la violencia simbólica como aquella que permite naturalizar la diferencia entre lo masculino y lo femenino, en donde la dominación masculina es producto de la violencia simbólica que estructura las relaciones desiguales entre los géneros, pues permite ver el cuerpo de la mujer como un objeto simbólico. Ahora bien, Méndez (2010) ha señalado lo siguiente:

Ciudad Juárez, y, en cierto modo, el territorio maquilador fronterizo, no tiene reglas que vayan más allá de las palabras. En el territorio se ha impuesto la inestabilidad de lo económico sobre la normatividad de lo político. El único principio inquebrantable es hacer exitosos los procesos de internacionalización del capital maquilador en la frontera, y parece que en este empeño poco importan las personas, en especial si son mujeres, y poco o nada se hace en el terreno de la infraestructura para lograr la seguridad ciudadana: todo es pasajero, un alargado presente que no termina por resolverse, un rito de paso, como se viene afirmando, detenido en su etapa liminal; la violencia simbólica no viene del o de los habitus que construyen los actores del territorio, proviene de ese momento desestructurado que vive cualquier sociedad de modernidad subordinada. (p. 36)

En este contexto, otros factores que favorecen la violencia de género son las migraciones masivas desde el sur del país hacia la ciudad fronteriza, aunque últimamente la migración viene también de otros países latinoamericanos. Así, Ciudad Juárez se ha convertido en lugar de tránsito, pues la mayoría de los migrantes tienen la intención de solicitar asilo en Estados Unidos. "[L]as razones que motivan esta migración es por la violencia y la falta de condiciones necesarias para vivir dignamente, lo cual impide su libre desarrollo en su lugar de origen" (Aguirre, 2018, p. 2). Sin embargo, un gran número de migrantes terminan insertándose en el mercado laboral informal de la ciudad, pues su proceso migratorio es lento y nada les garantiza la obtención del asilo, e incluso hay quienes han desistido del proceso migratorio.

Además de lo anterior, el narcotráfico es un fenómeno latente en la región y ha introducido en la sociedad la denominada "narcocultura". Para Boira (2015), esto implica la presencia de estructuras corruptas en el Estado y por ende impunidad, además de las condiciones de pobreza que pueden estar detrás de los feminicidios. Estos elementos constituyen ese sistema dinámico que en cierta medida ayuda a descifrar este tipo de violencia.

El fenómeno del feminicidio en Ciudad Juárez ha llegado hasta instancias internacionales como la Corte IDH, la cual tuvo conocimiento del Caso González y otras (Campo Algodonero) vs. México (2009), en donde concluyó que las jóvenes asesinadas fueron víctimas de la violencia contra la mujer que se vivía en esa ciudad fronteriza y que continúa latente hoy en día.

En dicho caso, el tribunal evidenció el incumplimiento del Estado mexicano en adoptar las medidas necesarias en asuntos de violencia contra las mujeres. En este orden, la Corte Interamericana de Derechos Humanos (2009) señala que los Estados parte están obligados a adoptar medidas para lograr una diligencia verdadera y oportuna en asuntos de violencia contra las mujeres. Para ello, hace especial énfasis en la importancia de contar con la normatividad adecuada para lograr una protección efectiva 
hacia las mujeres, sumada a políticas de prevención que analicen los factores de riesgo y se centren en brindar apoyo de manera inmediata. De igual forma, los Estados parte deben generar políticas centradas en la identificación de víctimas potenciales de este tipo de violencia, junto a las demás obligaciones contempladas en la Convención Americana y la Convención de Belém do Pará

Así entonces, el cumplimiento de la debida diligencia en casos de violencia contra la mujer incluye la obligación de adecuar el marco jurídico de protección con una aplicación efectiva. Nos detenemos en el marco jurídico, pues es importante mencionar que, si bien el Estado mexicano ha realizado un esfuerzo por adecuar formalmente su legislación, fortalecer sus instituciones y realizar diversas acciones orientadas a combatir la violencia por razón de género, también ha tardado en incorporar la expresión feminicidio al tipo penal, ya que en principio contaba únicamente con la agravante prevista en el artículo 126 del Código Penal, que señalaba lo siguiente:

Cuando la víctima del delito de homicidio sea del sexo femenino o menor de edad, se aplicarán las penas previstas en el segundo párrafo del artículo anterior.

Si además del homicidio, se cometen en perjuicio de la víctima otros delitos, deberá imponerse pena por cada delito cometido aun y cuando con ello se exceda el máximo de la pena de prisión. (Código Penal del Estado de Chihuahua, 2006, p. 35)

Este artículo fue analizado por la primera sala de la Suprema Corte de Justicia de la Nación, que emitió en julio de 2016 la tesis 1a. CCIII/2016 (10a.), bajo el siguiente rubro:

Homicidio. La agravante prevista en el artículo 126 del Código Penal para el estado de Chihuahua, cuando la víctima sea del sexo femenino, es discriminatoria por no contener el elemento finalista consistente en que el crimen se haya cometido por razón de género.

Por lo tanto, la Suprema Corte (2016) señala que la agravante prevista en el artículo 126 del Código Penal para el estado de Chihuahua, donde se establecía que, cuando la víctima fuera del sexo femenino, era discriminatoria, pues no contenía el elemento central, que consistía en que el delito se hubiera perpetrado por razones de género.

En ese sentido, la Suprema Corte (2016) determinó que, si bien la citada norma perseguía una finalidad imperiosa (lo cual era garantizar el cumplimiento y respeto del derecho de toda mujer a una vida libre de violencia y discriminación), la distinción que hacía la norma estaba basada en una categoría sospechosa de sexo, y no estaba directamente conectada con dicho fin. Por tanto, su formulación resultó sobreinclusiva, pues comprendía conductas no necesariamente vinculadas con privar de la vida a una mujer por razones de género, pero igualmente termina sancionándolas.

A partir del citado pronunciamiento de la Suprema Corte, el 28 de octubre de 2017, a través del decreto de reforma al Código Penal, el estado de Chihuahua incorporó el tipo penal, pero como homicidio de mujer por razones de género, adicionando con ello el artículo 126 bis y la adición de la fracción XI al artículo 136:

Artículo 126 bis. A quien prive de la vida a una mujer por razones de género, se le impondrá de treinta a sesenta años de prisión y la reparación integral del daño. Existen razones de género cuando se presente cualquiera de las siguientes circunstancias:

I. La víctima presente signos de violencia sexual de cualquier tipo.

II. Antes o después a la privación de la vida, a la víctima se le hayan infligido lesiones, mutilaciones o cualquier otro acto que atente contra la dignidad humana.

III. Existan antecedentes o datos que establezcan que el activo ejerció sobre la víctima de forma anterior a la privación de la vida, violencia física, psicológica, económica, patrimonial o de cualquier tipo; independientemente de que exista denuncia o haya sido del conocimiento de alguna autoridad.

IV. Por misoginia.

Además, se aumentará de uno a veinte años la pena de prisión impuesta, cuando concurra cualquiera de las siguientes circunstancias: 
I. Si una servidora o servidor público, aprovechándose de su cargo, interviniere en cualquier etapa del hecho delictivo.

II. Si fuere cometido por dos o más personas.

III. Si fuere cometido en presencia de personas con quienes la víctima tuviere vínculo de parentesco por consanguinidad, afinidad, civil o una relación afectiva o sentimental de hecho, a sabiendas de esta relación.

IV. Cuando la víctima fuere menor de edad o adulta mayor; de pueblos originarios; estuviere embarazada; sufriere discapacidad física, mental, intelectual o sensorial; o se encuentre en cualquier otra condición especial.

V. Exista o haya existido entre el activo y la víctima una relación de parentesco por consanguinidad o afinidad, de matrimonio, concubinato, sociedad de convivencia, noviazgo, cualquier otra relación de hecho o amistad, laboral, docente, o cualquier otra que implique confianza, subordinación o superioridad.

VI. Si la víctima, por cualquier medio, fue sometida a prácticas que alteraran su estructura corporal con menosprecio al cuerpo de la víctima.

VII. Si la víctima se encontraba bajo el cuidado o responsabilidad del agente, utilizando los medios o circunstancias que su cargo o situación personal le proporcionen.

VIII. La víctima haya sido incomunicada, cualquiera que sea el tiempo previo a la privación de la vida.
IX. El cuerpo de la víctima sea expuesto, depositado, arrojado o exhibido en circunstancias tales que pueda ser visto por otras personas.

X. El cuerpo de la víctima sea enterrado u ocultado.

XI. Cuando la víctima se encuentre en estado de indefensión.

Si faltaren las razones de género, se estará a la punibilidad prevista para el homicidio

Artículo 136. El homicidio y las lesiones son calificadas cuando se cometan con: premeditación, ventaja, traición, alevosía, retribución, por el medio empleado, saña o en perjuicio de servidores públicos que se encarguen de la administración o procuración de justicia, o de periodistas; así mismo, en los supuestos de las fracciones $\mathrm{X}$ y $\mathrm{XI}$ del presente artículo:

I a X ...

XI. Cuando se cometa por razones de género contra una persona con identidad de género distinta a su sexo. (Código Penal del Estado de Chihuahua, 2017, p. 35)

En el caso de Chihuahua, es claro que incorpora el tipo penal como homicidio de mujer por razones de género, y que hasta el cierre de esta investigación deja a un lado la expresión feminicidio, a pesar de que otras entidades federativas sí han adoptado el término de feminicidio.

A continuación, presentamos un cuadro comparativo con los tipos penales de algunas entidades federativas de manera enunciativa, mas no limitativa.

Tabla 1. El tipo penal de feminicidio en diversas entidades federativas

\begin{tabular}{|c|c|}
\hline \multirow[t]{4}{*}{$\begin{array}{l}\text { Código } \\
\text { Penal del } \\
\text { estado de } \\
\text { Yucatán } \\
\text { *Adición } \\
\text { en el } 2012\end{array}$} & $\begin{array}{l}\text { Feminicidio } \\
\text { Artículo } 394 \text { Quinquies. Comete el delito de feminicidio quien dolosamente prive de la vida a una } \\
\text { mujer por razones de género. Se considera que existen razones de género cuando concurra alguna de } \\
\text { las circunstancias siguientes: }\end{array}$ \\
\hline & $\begin{array}{l}\text { I. La víctima presente signos de violencia sexual de cualquier tipo, previas o posteriores a la privación } \\
\text { de la vida. }\end{array}$ \\
\hline & $\begin{array}{l}\text { II. A la víctima se le hayan practicado mutilaciones genitales o de cualquier otro tipo, cuando estas } \\
\text { impliquen menosprecio a la mujer o a su cuerpo. }\end{array}$ \\
\hline & $\begin{array}{l}\text { III. Existan antecedentes de violencia familiar, laboral o escolar, motivada por razones de género, del } \\
\text { sujeto activo en contra de la víctima. }\end{array}$ \\
\hline
\end{tabular}


IV. La pretensión infructuosa del sujeto activo de establecer o restablecer una relación de pareja o de intimidad con la víctima.

V. Haya existido entre el sujeto activo y la víctima una relación sentimental, afectiva o de confianza.

VI. Existan datos que establezcan que hubo amenazas relacionadas con el hecho delictuoso, acoso o lesiones del sujeto activo en contra de la víctima.

VII. La víctima haya sido incomunicada, cualquiera que sea el tiempo previo a la privación de la vida.

VIII. El cuerpo de la víctima sea expuesto o exhibido en un lugar público.

A quien cometa el delito de feminicidio se le impondrán de treinta y dos a cuarenta y cinco años de prisión y de mil quinientos a dos mil quinientos días-multa. Si entre el sujeto activo y la víctima existió una relación de parentesco por consanguinidad en línea recta, sin limitación de grado, o colateral hasta el cuarto grado o por afinidad hasta el cuarto grado; laboral, docente o sentimental, se impondrá una pena de prisión de cuarenta a sesenta años de prisión y de mil quinientos a dos mil quinientos días-multa. Además de las sanciones descritas en este artículo, el sujeto activo perderá todos los derechos con relación a la víctima, incluidos los de carácter sucesorio. Las autoridades investigadoras competentes, cuando se encuentren ante un probable delito de feminicidio deberán aplicar el protocolo correspondiente a dicho delito; en caso de que no se acredite el feminicidio, se aplicarán las reglas del homicidio.

Artículo 394 Sexies. Al servidor público que retarde o entorpezca maliciosamente o por negligencia la procuración o administración de justicia, cuando se trate de la investigación de un delito de feminicidio, se le impondrán de tres a ocho años de prisión y de quinientos a mil quinientos días-multa, además será destituido e inhabilitado de tres a diez años para desempeñar otro empleo, cargo o comisión públicos

Código

Penal del

estado de

Veracruz

de Ignacio

de la Llave

*Adición:

29 de

agosto de

2011

\section{Capítulo VII bis}

Feminicidio

Artículo 367 bis. Comete el delito de feminicidio quien por razones de género priva de la vida a una mujer. Existen razones de género cuando se presenta alguna de las siguientes circunstancias:

I. Exista o haya existido entre el activo y la víctima una relación de parentesco por consanguinidad o afinidad, de matrimonio, concubinato, noviazgo o cualquier otra relación de hecho o amistad;

II. Exista o haya existido entre el activo y la víctima una relación laboral, escolar, o cualquier otra que implique confianza, subordinación o superioridad;

III. La víctima presente signos de violencia sexual de cualquier tipo;

IV. A la víctima se le hayan infligido lesiones infamantes, degradantes o mutilaciones previamente a la privación de la vida, o se realicen marcas infamantes o degradantes sobre el cadáver, o éste sea mutilado;

V. Hayan existido amenazas, acoso o lesiones del sujeto activo en contra de la víctima;

VI. El cuerpo de la víctima sea expuesto o arrojado en un lugar público; o

VII. La víctima haya sido incomunicada.

(Reformado, segundo párrafo; G.O. 1 de diciembre de 2015)

A quien cometa el delito de feminicidio se le impondrá una sanción de cuarenta a setenta años de prisión. Además de la sanción descrita en el presente artículo, el imputado perderá todos los derechos con relación a la víctima.

Para el supuesto de la fracción I perderá también los derechos de familia y los de carácter sucesorio.

(Adicionado, tercer párrafo; G.O. 1 de diciembre de 2015)

En la configuración del delito, no es necesario que se acredite la personalidad misógina del inculpado.

Código

Penal del

estado de

Guerrero

\section{Artículo 135. Feminicidio}

Comete el delito de feminicidio quien, por razones de género, prive de la vida a una mujer. Existen razones de género cuando ocurra cualquiera de los supuestos siguientes:

I. La víctima presente señales de violencia sexual de cualquier tipo; (Reformado P.O. No. 100 alcance IVv, de fecha viernes 15 de diciembre de 2017)

II. A la víctima se le hayan infligido lesiones o mutilaciones infamantes, denigrantes o degradantes, previas o posteriores a la privación de la vida o actos de necrofilia;

III. Existan antecedentes o datos de cualquier tipo de violencia, cometido en el ámbito familiar, laboral o escolar, cometido por el sujeto activo en contra de la víctima;

IV. Existan datos o referencias que establezcan que hubo amenazas relacionadas con el hecho delictuoso, acoso o lesiones del sujeto activo en contra de la víctima;

V. Haya existido entre el sujeto activo y la víctima una relación de familia, sentimental, afectiva o de confianza; (Reformado P.O. No. 100 alcance IV, de fecha viernes 15 de diciembre de 2017)

VI. El cuerpo de la víctima sea expuesto, arrojado o exhibido en un lugar público; (Reformado P.O. No. 100 alcance IV, de fecha viernes 15 de diciembre de 2017)

VII. La víctima haya sido incomunicada, cualquiera que sea el tiempo previo a la privación de la vida; 


\begin{abstract}
(Reformado párrafo tercero, P.O. No. 100 alcance IV, de fecha viernes 15 de diciembre de 2017)
A quien cometa el delito de feminicidio se le impondrán de cuarenta a sesenta años de prisión y multa de quinientos a mil veces de la Unidad de Medida y Actualización. Además de las sanciones señaladas en el presente artículo, la persona sentenciada perderá todos sus derechos con relación a la víctima, incluidos los de carácter familiar y sucesorio.

(Adicionado párrafo quinto, P.O. No. 100 alcance IV, de fecha viernes 15 de diciembre de 2017)

Al servidor público que retarde o entorpezca maliciosamente o por negligencia la procuración o administración de justicia se le impondrán pena de prisión de tres a ocho años y multa de quinientos a mil quinientos veces el valor de la Unidad de Medida y Actualización, además será destituido e inhabilitado de tres a diez años para desempeñar otro empleo, cargo o comisión públicos.
\end{abstract}

Fuente: elaboración propia con información de los Códigos Penales de las entidades federativas citadas.

A partir de lo anterior podemos concluir que los tipos penales varían en las entidades federativas, y que, a diferencia del Código Penal del estado de Chihuahua, otros estados sí manejan el término feminicidio, mientras que, al cierre de esta investigación, Chihuahua aún refiere "homicidio de la mujer por razones de género". Además, en el caso del Código Penal de Chihuahua se manejan más supuestos que agravan la pena. Sin embargo, no existe un artículo que sancione a los servidores públicos que retarden o entorpezcan maliciosamente o por negligencia la procuración o administración de justicia, cuando se trate de la investigación de un delito de feminicidio, lo cual sí está contemplado por los códigos que a manera de ejemplo se expusieron en el cuadro comparativo de la tabla 1.

Ahora bien, a partir de estas similitudes y diferencias en los Códigos Penales, se debe tratar de homologar el tipo penal, para que tenga los mismos elementos y características en todas las entidades federativas. A medida que se contemplen los mismos supuestos normativos, el feminicidio podrá ser más visible, lo que facilitará la investigación y la procuración de justicia. Si bien es cierto que la penalización no va a resolver el problema, sí es un insumo necesario para el diseño de una política integral que logre erradicar la violencia de género en la entidad.

\section{La percepción de los juzgadores y fiscales ante el tipo penal de homicidio por razones de género}

Para conocer las percepciones de los agentes involucrados con el tipo penal de homicidio por razones de género en el Código Penal del Estado de Chihuahua, se realizaron entrevistas semiestructuradas. Para la realización de dichas entrevistas se buscaron funcionarios públicos que laboraran en la Fiscalía Especializada en Atención a Mujeres Víctimas del Delito por Razón de Género, zona norte, y funcionarios del Poder Judicial del estado de Chihuahua que laboraran en el Distrito Judicial Bravos (donde se ubica Ciudad Juárez) y que hubiesen llevado procesos por el delito de homicidio por razones de género. Para ello se realizaron peticiones por escrito a ambas dependencias, y se lograron acercamientos con distintos funcionarios.

En un primer momento se entrevistó al coordinador de la Unidad de Homicidios de Mujeres por razones de Género de la mencionada Fiscalía, zona norte, el licenciado Noel Rodríguez Vargas, y posteriormente al magistrado Marco Tulio Cano Corral, de la Primera Sala Penal Regional en el estado.

En estas conversaciones se abordaron distintas áreas y categorías, la primera de las cuales hizo referencia al término de feminicidio en relación con el homicidio por razones de género. Al respecto, se les preguntó si era conveniente adecuar el término y qué implicaciones conllevaría dicho cambio, a lo que Rodríguez contestó: "No hay problema como está tipificado, está bien porque al fin de cuentas se traduce en feminicidio. Independiente de los términos, lo importante es hacer una investigación científica". (Rodríguez Vargas, comunicación personal, 1 de mayo de 2020). Para el Fiscal, no es necesario el cambio, puesto que el fin es el mismo y el trabajo de investigación también.

Por su lado, el magistrado Cano Corral respondió lo siguiente: "Prefiero que se adecue a feminicidio porque se trata de visibilizar de muchas formas y de muchos aspectos, es perfectible hacerle mejoras al tipo penal" (Cano Corral, comunicación personal, 1 de mayo de 2020).

Por otra parte, se les cuestionó a los participantes si consideraban necesario ampliar los postulados del artículo 126 bis e incluir un artículo para sancionar a los servidores públicos que retarden o entorpezcan 
maliciosamente o por negligencia la procuración o administración de justicia durante la investigación de un delito de feminicidio. Rodríguez Vargas respondió lo siguiente en lo que respecta a ampliar los supuestos:

Sí, considero que debe agregarse cuando la víctima es privada de la vida por su pareja sentimental, porque nosotros lo tenemos como agravante y debiese agregarse para no tener tanta dificultad en la integración de la investigación. Eso nos ayudaría porque no podemos encuadrarla en los primeros supuestos, y tenemos que motivar más en el caso y nos vemos más apretados y batallamos para acreditarlo bien, y tenemos que imputarle con el 125 del Código Penal agravado. (Rodríguez Vargas, comunicación personal, 1 de mayo de 2020)

Precisó, además, que le parece adecuado agregar un último párrafo en el que se castigue a los funcionarios que fueron omisos o negligentes en su trabajo, pues así lo establece la sentencia del Campo Algodonero.

Por su parte, el magistrado Marco Tulio considera importante incorporar la sanción a los funcionarios, que la voluntad no está en el discurso sino en el presupuesto, por lo que se requiere mayor personal en el área de la Fiscalía: “Urgen ministerios públicos y policías, esa es la gran prioridad, hay un rezago de 40 mil carpetas de investigación sin procesar debido a la falta de personal y equipo" (Cano Corral, comunicación personal, 1 de mayo de 2020)

Frente a las experiencias en investigación y enjuiciamiento, Rodríguez refirió que en los casos de feminicidio casi siempre hay violencia familiar. Al respecto, señala que los homicidios de mujeres por razones de género son generalizados y agregó lo siguiente:

De los 160 casos en donde intervinimos el año pasado, solo 22 fueron feminicidios [...]. En el 2018, de los cincuenta casos que llevamos, solo 16 fueron por razones de género. Hay una tendencia a aumentar los números de feminicidios en la ciudad, pero muchos de los homicidios dolosos de mujeres tienen que ver con el consumo y tráfico de drogas. (Rodríguez Vargas, comunicación personal, 1 de mayo de 2020)
También se cuestionó a los participantes sobre la pertinencia de agregar a la norma que, para la configuración del delito, no sea necesario acreditar la personalidad misógina del inculpado, puesto que hay otros códigos penales que sí lo señalan. Al respecto, Rodríguez señaló que en su unidad se ha acreditado la misoginia en la práctica:

Sí lo hemos acreditado, pero es complejo porque tiene mucha subjetividad, porque el juzgador tiene que tener perspectiva de género, porque si no, es complicado. En los casos en donde no los vinculan por la personalidad misógina, terminan vinculándolo por otro supuesto. Este complejo es muy subjetivo y dependemos de amigos y familiares que nos den el antecedente. (Rodríguez Vargas, comunicación personal, 1 de mayo de 2020)

Al contrario de Rodríguez, el magistrado Marco Tulio comentó: "No es complicado la misoginia, ese tipo de expresiones están muy claras, no es tan complicado, es muy sencillo y con cuestiones objetivas" (Cano Corral, comunicación personal, 1 de mayo de 2020)

Por consiguiente, independientemente de si acreditar la conducta misógina del inculpado es una tarea fácil o no, esta no resulta necesaria para configurar el tipo penal, pues existen múltiples supuestos que se pueden acreditar sin mayor dificultad.

De las percepciones de los participantes se concluye que el tipo penal es perfeccionable, pero sobre todo es indispensable que la voluntad legislativa vaya acompañada por un mayor presupuesto para equipar a la Fiscalía, pues de nada sirve un cambio en el papel si el área operativa no es eficaz. Incluso se hace necesaria la prevención del delito de violencia familiar, pues este delito suele ser la antesala del feminicidio, como ha quedado claro. Por ello, se requieren políticas integrales que atiendan la prevención, la investigación y la sanción.

\section{CONCLUSIONES}

Para visibilizar el feminicidio en el estado de Chihuahua en mayor medida, es importante desarrollar una reforma integral que incorpore la expresión "feminicidio" en el artículo 126 bis, y que ayude a delimitar los supuestos para evitar la confusión y las 
distintas interpretaciones. Pese a que, para enfrentar el problema no se requiere únicamente resolverlo por la vía penal, esta resulta indispensable para llevar justicia a las víctimas y contribuir a generar conciencia social sobre el problema.

Además de esto, debe atenderse el tema del presupuesto destinado al aparato de investigación, ya que de las entrevistas realizadas a los participantes se desprende la carencia que enfrenta la Fiscalía Especializada en Atención a Mujeres Víctimas del Delito por Razones de Género. Esto ha ocasionado un rezago de 40 mil carpetas de investigación sin procesar, debido a la falta de personal y equipo, situación que implica la victimización secundaria por la inactividad estatal.
Se requieren acciones concretas que atiendan la complejidad y la magnitud de la violencia contra las mujeres y la gravedad del feminicidio en la entidad de Chihuahua, a través de políticas públicas que tengan como eje trasversal la perspectiva de género y los derechos humanos, que abonen a la profesionalización de las autoridades y a la concientización a la sociedad sobre la violencia de género. No es aceptable contribuir aún más a la cultura del miedo a través del fenómeno del feminicidio, como lo señalan Pineda y Herrera (2007). No es aceptable continuar con la estigmatización de Ciudad Juárez como la entidad de "las muertas de Juárez", en donde se ha ido suponiendo la rendición individual y colectiva. Es necesario diseñar una política integral que enfrente las causas de la violencia, que busque prevenir, sancionar y erradicar la violencia. 


\section{REFERENCIAS}

Aguirre Bonilla, O. (2020). La violencia feminicida en Ciudad Juárez: iniciativa spotlight en México. En E.C. Pérez-Luño Enrique C. y M. Domínguez Barragán María (Edits.). La administración de justicia en España y en América (p.p. 11-24). Sevilla: Editorial Astigui.

Abramovich, V. (2010). Responsabilidad estatal por violencia de género: comentarios sobre el caso "Campo Algodonero" en la Corte Interamericana de Derechos Humanos. Anuario de Derechos Humanos, 6, 167-182.

Aguirre Bonilla, O. (2014). Estado mexicano: lejos de cumplir íntegramente la sentencia de la $\mathrm{CIDH}$ en el caso González y otras. Via luris, 17, 169-182.

Aguirre Bonilla, O. (2018). Migrantes seguros. Recuperado de: https://diario.mx/Opinion/201811-15_1eacbb9d/migrantes-seguros-/. Consultado Mayo 2020.

Aguirre Bonilla, O. (2020). La violencia feminicida en Ciudad Juárez: iniciativa spotlight en México. En E. C. Pérez-Luño y M. Domínguez Barragán (Edits.), La administración de justicia en España y en América (pp. 11-24). Sevilla: Astigui.

Boira, S., Marcuello-Servós, C., Otero L., Sanz Barbero, B. \& Vives-Cases, C. (2015). Femicidio y feminicidio: un análisis de las aportaciones en clave iberoamericana. Revista Internacional de Trabajo Social y Ciencias Sociales, 10, 27-46.

Comisión Económica Para América Latina (CEPAL). (2018). Al menos 2.795 mujeres fueron víctimas de feminicidio en 23 países de América Latina y el Caribe en 2017. Recuperado de https://www.cepal.org/es/comunicados/ cepal-al-menos-2795-mujeres-fueron-victi- mas-feminicidio-23-paises-america-latinacaribe. Consultado en mayo 2020

Corte Interamericana de Derechos Humanos. (2003). México, muertes intolerables, Diez años de desapariciones y asesinatos en ciudad Juárez y Chihuahua. México D. F.: Amnistía Internacional.

Corte Interamericana de Derechos Humanos. Caso González y otras (Campo Algodonero vs. México). Sentencia del 16 de noviembre de 2009.

González Rodríguez, S. (2002). Huesos en el desierto. Barcelona: Anagrama.

Lagarde y de los Ríos, M. (2006). Presentación a la Edición en español. En J. Radford y D.E.H. Russell (Edits.), Feminicidio. La política del asesinato de las mujeres (pp. 12-18). México: Centro de Investigaciones Interdisciplinarias en Ciencias y Humanidades de la Universidad Nacional Autónoma de México.

Lagarde y de los Ríos, M. (2012). El feminismo en mi vida: hitos, claves y topías. México D. F.: Inmujeres DF.

Méndez, L. H. (2010). Territorio maquilador y violencia. El caso de Ciudad Juárez. El Cotidiano, 164, 27-40.

Monárrez, J. E. (2000). La cultura del feminicidio en Ciudad Juárez, 1993-1999. Frontera Norte, 12(23), 87-117

Organización de los Estados Americanos. Declaración sobre el Femicidio. 15 de agosto de 2008.

Pineda, S. \& Herrera, L. A. (2007). Ciudad Juárez: Las sociedades de riesgo en la frontera norte de México. Fermentum, 17(49), 419-433.

Russell, D. E. H. (2012) The vital relevance of femicide to domestic violence. Ponencia presentada en The Annual National Coalition on Domestic Violence, Denver Colorado, EUA. 
Segato, R. L. (2003). Las estructuras elementales de la violencia. Ensayos sobre género entre la antropología, el psicoanálisis y los derechos humanos. Buenos Aires: Universidad Nacional de Quilmes; Prometeo.

Segato, R.L. (2016). La guerra contra las mujeres. Madrid: Traficantes de Sueños.

Suprema Corte de Justicia de la Nación, Constitucional Penal. Décima época, Registro 2012108, Libro 32, Julio de 2016, Tomo I, Tesis: 1a. CCIII/2016 (10a.) Página: 319.

Radford J. \& Russell D. E. H. (1992). Femicide: The Politics of Woman Killing. Nueva York: Twayne Publishers.

Vargas Martínez, F. C. (2018). Violencia feminicida como dispositivo de poder necropolítico. Experiencias activistas feministas. Tesis de maestría Universidad Autónoma del Estado de Hidalgo, Pachuca de Soto, México.

Washington Valdez, D. (2005). Cosecha de mujeres. Safari en el desierto mexicano. México: Océano. 